\title{
Male and female observers evoke different responses from monkeys
}

\author{
G. MITCHELL, SHEILA STEINER, BRAD DOWD, CHRIS TROMBORG, and FRED HERRING \\ University of California, Davis, California
}

(Robert B. Post, Sponsor)

\begin{abstract}
Golden-bellied mangabey (Cercocebus galeritus chrysogaster) adult females observed at the zoo threatened female observers more than they threatened male observers. Theory in behavioral primatology as well as research design decisions may be affected by this difference, especially if other primates respond to human sex differences in a manner similar to these mangabeys.
\end{abstract}

In attempting to evaluate the entire socioecology of the zoo environment of the golden-bellied mangabey (Cercocebus galeritus chrysogaster), we began by concentrating on aggressive behavior. The aggressive behaviors of these zoo mangabeys differed with the histories of the individual animals, the degree of perineal swelling of the females, the presence or absence of infants, and the nature of distractions near their enclosures (Mitchell, Soteriou, Towers, Kenney, \& Schumer, 1987).

Mangabey aggressive behavior also differed with the sex of the animal, with males usually being more aggressive. Sex persisted as an influence across different living conditions, different lengths of time in captivity, different rearing conditions, presence or absence of offspring, and even across different points in time during active mating (Mitchell, Towers, Soteriou, Schumer, Kenney, Gusé, \& Dillin, 1988).

The targets of mangabey aggression, as assessed by aggressive facial displays, often included people. But different people were aggressed in different ways by the mangabeys. In fact, differences between visitor-directed and observer-directed aggressive displays were important in evaluating the effects of cage changes (Mitchell, Soteriou, Kenney, Towers, Schumer, Dillin, \& Gusé, 1988). Visitors were salient stimuli in the lives of these zoo mangabeys, and numbers of visitors were very much related to the location of the enclosure and the sequence in which the enclosures could be visited (Mitchell, Herring, Tromborg, \& Neville, 1990; Mitchell, Obradovich, Sumner, DeMorris, Lofton, Minor, Cotton, \& Foster, 1990).

A faculty research grant from the University of California made this research possible. We thank especially Stephanie Obradovich, without whom this research would not have been completed. We also thank Maria Aguilera, Latrece Cotton, Kristine DeMorris, Todd Foster, Pha Green, Lorraine Jordan, Lisa Lofton, Jonathan Minor, Diana Sumner, and Steve Towers for observations and other contributions. We also owe the keepers Laurie Neville and Leslie Field our gratitude for their cooperation. Director Maria Baker and curator Jane Hansjergen were supportive. We appreciate the timely manuscript preparation of Martie Johnson. Correspondence may be addressed to G. Mitchell, Department of Psychology, University of California, Davis, CA 95616-8686.
The behavior of the visitors toward the mangabeys depended on what else the visitors were occupied in doing besides viewing the animals (Burns, Mitchell, \& Obradovich, 1989), and this in turn depended on the sex of the visitor.

Because visitors were so salient a stimulus and because both sex of mangabey and sex of visitor seemed so important to the aggressive behavior of each species, we concentrated on the sex differences in aggressive interactions between mangabeys and visitors. Beginning with mangabey aggressive responses to visitors, we noted that when animals were moved to enclosures attended by more visitors, they decreased their aggressive facial displays toward primates in neighboring cages yet increased their aggressiveness within their own groups as well as toward the increased numbers of visitors (Mitchell, Herring, Obradovich, Tromborg, Dowd, Neville, \& Field, 1991; Mitchell, Herring, Tromborg, Dowd, Steiner, \& Obradovich, 1991).

That it was the visitors and not people in general, like keepers or observers, that received the increases in aggressive displays was much apparent in a study that compared responses to different kinds of human stimuli in the mangabey's surroundings. Keepers and observers did not differ from one another in frequency of being objects of aggressive display, yet they both received far fewer threats than did visitors. Keepers were treated like cage-mates, and observers were treated like familiar animals of another group. Visitors were treated like strangers (Mitchell, Obradovich, \& Herring, 1991). But what of the sex differences?

In their responses to these human visitor strangers, mangabeys continued to show sex differences, but, interestingly, so did these visitors in their responses to the mangabeys. Adult male and/or female golden-bellied mangabeys directed more frequent aggressive facial displays toward visitors of their sex than toward visitors of the other sex. The human visitors showed the same pattern, with men harassing male mangabeys and women harassing female mangabeys. So all targets of mangabey aggression did not produce the same mangabey sex difference in numbers of threats (Mitchell, Herring, \& Obradovich, 1991). There are similar "like-threaten-like" proclivities in the nor- 
mal social systems of many cercopithecids, both in the wild and in captivity (cf. Angst, 1973; Bernstein, Gordon, \& Rose, 1974; Southwick \& Siddiqi, 1972).

Although, admittedly, human visitors were threatened much more frequently than were observers, it became essential (at least to us) that we examine our observerdirected threat data for the possible presence of similar like-threaten-like tendencies in the mangabeys. If mangabeys also have within-sex preferences for observerdirected threats, this would give strong evidence for control of a specific kind of observer effect in observational animal research. Both method and theory might be affected by such like-sex inclinations.

\section{METHOD}

\section{Subjects}

The subjects were five groups of golden-bellied mangabeys (Cercocebus galeritus chrysogaster). The sex, age, and date of observation of each of the mangabeys are listed in Table 1. Only the adult (4 years and older) male and female mangabeys were used as subjects in this study. The human subjects were 8 different observers, 5 females and 3 males, each of whom was an undergraduate psychology major at the University of California, Davis (ages 20-25).

\section{Enclosure}

Each enclosure was a different wing of two four-wing monkey complexes; three of the enclosures were in one complex and two in another. The wings were at $90^{\circ}$ angles and were $5.8 \mathrm{~m}$ long, $2.69 \mathrm{~m}$ wide, and $3.1 \mathrm{~m}$ high. Floors were cement, and ceilings and walls were chain link, except for one brick wall where the mangabeys could enter their dens. Each enclosure contained three branches and an occasional bucket of water and ball. The enclosures were illustrated and described in more detail elsewhere (Mitchell, Herring, Tromborg, \& Neville, 1990).

\section{Procedures}

Data sheets were used for the detailed recording of every brow threat and/or open-mouth threat directed toward observers. Each data sheet had 25 rows, 1 row for each face threat seen. Brow threats and/or openmouth threats were defined in the classical way (Hinde \& Rowell, 1962; Redican, 1975). If both threat components occurred, both were scored.

Table 1

Group, Sex, and Age of Golden-bellied Mangabeys at the Sacramento Zoo between February and April 1984 and February and September 1988

\begin{tabular}{cllcl}
\hline Group & Subject & Sex & Age in Years & When Observed \\
\hline 1 & Pino & Male & 5,9 & 1984 and 1988 \\
1 & Wendy & Female & 5,9 & 1984 and 1988 \\
1 & Chuck & Male & 3 & Not a subject \\
1 & Howard & Male & $11 \frac{1}{2}$ & Not a subject \\
2 & June & Female & 18 & 1988 \\
$2 / 3$ & Leslie & Female & 4 & 1988 \\
2 & Murray & Male & $21 \frac{1}{2}$ & Not a subject \\
2 & Rafiki & Female & 1 & Not a subject \\
3 & Dutch & Male & 7 & 1988 \\
3 & Julia & Female & $71 / 2$ & 1988 \\
$2 / 3$ & Leslie & Female & 4 & 1988 \\
4 & Morris & Male & $7-9$ & 1984 \\
4 & Mary & Female & $7-9$ & 1984 \\
5 & Hal & Male & 14 & 1984 \\
5 & Maria & Female & 14 & 1984 \\
5 & no name & Female & $31 / 2$ & Not a subject \\
5 & unnamed & Male & 2 & Not a subject \\
5 & infant & Female & 2 mos. & Not a subject \\
\hline
\end{tabular}

Table 2

Chi-square Analyses of Mangabey-to-Observer Threats: Contingency Tables Are Organized by Sex of Mangabey and Sex of Observer

\begin{tabular}{llccc}
\hline \multirow{2}{*}{$\begin{array}{c}\text { Mangabey } \\
\text { Subjects }\end{array}$} & \multicolumn{2}{c}{ Observers } & & \\
\cline { 2 - 4 } Adult males & 42 sessions & 112 sessions & 1.37 & n.s. \\
& 24 threats & 90 threats & & \\
Adult females & 60 sessions & 221 sessions & 20.90 & .001 \\
& 12 threats & 184 threats & & \\
& $\chi^{2}=6.93$ & $\chi^{2}=0.04$ & & \\
& $p<.01$ & n.s. & & \\
\hline
\end{tabular}

* Overall chi-square, even with frequencies of threats adjusted to the most conservative $\mathbf{4 2}$ sessions (the lowest or most conservative number of sessions of the four categories), revealed a statistically significant sex of observer $\times$ sex of mangabey interaction $\left[\chi^{2}(1, n=101)=5.92\right.$, $p<.05]$.

Each observation session lasted 15 min per enclosure, and each 15-min session was on one focal animal. None of the sessions demanded more than 25 rows of a data sheet for observer-directed threats, which were less frequent than visitor-directed threats (Mitchell, Obradovich, \& Herring, 1991). A total of 43515 -min sessions was accumulated, 333 by female observers (112 on male mangabeys and 221 on female mangabeys) and 102 by male observers ( 42 on male mangabeys and 60 on female mangabeys). The sum of the brow threats and open-mouth threats was used in comparisons by sex. The brow threats and open-mouth threats were very reliably measured by the 8 different observers because these were the only two mangabey behaviors recorded. Chi-square analyses with total frequencies of threats corrected for unequal session numbers for men and women and for male and female mangabeys were used to compare numbers of threats by mangabeys to male and female observers.

\section{RESULTS}

Adult male mangabeys threatened men and women observers equally often $\left[\chi^{2}(1, n=268)=1.37\right.$, n.s.; see Table 2]. Adult female mangabeys, on the other hand, threatened women much more frequently than they threatened men $\left[\chi^{2}(1, n=477)=20.90, p<.001\right]$.

Male observers were threatened significantly more often by male mangabeys than by female mangabeys $\left[\chi^{2}(1, n=\right.$ $138)=6.93, p<.01]$, but female observers were threatened just as much by female mangabeys as they were by males $\left[\chi^{2}(1, n=507)=0.04\right.$, n.s.; see Table 2].

In examining the four possibilities-male mangabey threatens man, male mangabey threatens woman, female mangabey threatens man, and female mangabey threatens woman-only the category female mangabey threatens man appeared to be a significantly different category (see Table 2) when the frequencies were corrected for numbers of sessions for men and women observers and for male and female mangabeys, respectively. Female mangabeys threatened male observers much less than was the case for the other categories. Clearly, there is a significant sex of observer $X$ sex of mangabey interaction.

\section{DISCUSSION}

Recall that in our previous studies of mangabey responses to visitors (Mitchell, Herring, \& Obradovich, 1991), we found more frequent aggressive facial displays directed toward visitors of the same sex as the 
threatening mangabeys. This means that with the visitors as well as with the observers, female mangabeys threatened women more than they threatened men. The visitors, however, also selectively harassed in a like-threaten-like manner. The female mangabeys could have been responding more to visitor women because the women in turn were threatening them.

In the current study, we used neutral, nonharassing observers. Still, the female mangabeys tended to threaten women more than they threatened men. It is highly unlikely that this is a matter of different perceptions by the men and women, as we will see in the discussion below.

It is probable that like-threaten-like is a natural inclination in the social systems of wild and captive cercopithecids. Many researchers have noted like-sex aggressive tendencies in this family of primates (Angst, 1973; Bernstein et al., 1974; Southwick, 1967; Southwick \& Siddiqi, 1972), including another species of mangabey, the sooty mangabey (Cercocebus atys) (see Bernstein, 1971). What is intriguing here is that the tendency appears to generalize across species. The fact that one of the species is Homo sapiens has many implications.

It is no secret within disciplines related to behavioral primatology that claims have been made of a difference between how male and female primatologists view the behaviors of their nonhuman primate subjects (see Small, 1984). If they do differ, perhaps it is because the subjects themselves, the monkeys, view men and women differently. If women are threatened by female monkeys and men are not, it might not be surprising that women might see female primates as being more aggressive than men might. Theory as well as good research design may be affected by such a difference. Special care must be given to balancing observer sex with respect to the sex of the animal being observed.

\section{REFERENCES}

ANGST, W. (1973). Pilot experiments to test group tolerance to a stranger in wild Macaca fascicularis. American Journal of Physical Anthropology, 38, 625-630.

BERNSTEIN, I. S. (1971). The influence of introductory techniques on the formation of captive mangabey groups. Primates, 12, 33-44.

Bernstein, I. S., Gordon, T. P., \& Rose, R. M. (1974). Aggression and social controls in rhesus monkey (Macaca mulatta) groups revealed in group formation studies. Folia Primatologica, 21, 81-107.

Burns, A. L., Mitchell, G., \& Obradovich, S. (1989). Of sex roles and strollers: Female and male attention to toddlers at the zoo. Sex Roles, 20, 309-315.

Chamove, A. S., Hosey, G. R., \& Schaetzel, P. (1988). Visitors excite primates in zoos. Zoo Biology, 9, 55-63.

Hinde, R. A., \& Rowell, T. E. (1962). Communication by posture and facial expression in the rhesus monkey. Proceedings of the Zoological Society of London, 138, 1-21.
Mitchell, G., Herring, F., \& Obradovich, S. (1991). Like-threatenlike in mangabeys and people. Unpublished manuscript،

Mitchell, G., Herring, F., Obradovich, S., Tromborg, C., Dowd, B., Neville, L., \& Field, L. (1991). Effects of visitors and cage-changes on aggressive, sexual, and play behaviors in three groups of golden-bellied mangabeys (Cercocebus galeritus chrysogaster) at the Sacramento Zoo. Unpublished manuscript.

Mitchell, G., Herring, F., Tromborg, C., Dowd, B., Steiner, S., \& OBRADOVICH, S. (1991). Targets of aggressive facial displays by golden-bellied mangabeys (Cercocebus galeritus chrysogaster) at the Sacramento Zoo. Unpublished manuscript.

Mitchell, G., Herring, F., Tromborg, C., \& Neville, L. (1990). The importance of sequence of cage visitation in a zoo. Animal Keeper's Forum, 17, 374-383.

Mitchell, G., Obradovich, S., Herring, F. (1991). Threats to observers, keepers, visitors and others by zoo mangabeys. Unpublished manuscript.

Mitchell, G., Obradovich, S., Sumner, D., DeMorris, K., Lofton, L., Minor, J., Cotron, L., Foster, T. (1990). Cage location effects on visitor attendance at three Sacramento Zoo mangabey enclosures. Zoo Biology, 9, 55-63.

Mrtchell, G., SOTERIOU, S., KenNeY, L., Towers, S., Schumer, C., Dilun, L., \& Gusé, K. (1988). Golden-bellied mangabeys (Cercocebus galeritus chrysogaster) at the Sacramento Zoo: Adult heterosexual pairs. Zoo Biology, 7, 1-13.

Mrtchell, G., SOTERIOU, S., Towers, S., KenNey, L., \& SCHumer, C. (1987). Descriptive accounts of the behavior of breeding and nonbreeding pairs of golden-bellied mangabeys (Cercocebus galeritus chrysogaster). Zoo Biology, 6, 391-399.

Mrtchell, G., ToWers, S., Soteriou, S., Schumer, C., KenNey, L., Gusé, K., \& DiluIN, L. (1988). Sex differences in behavior of endangered mangabeys (Cercocebus galeritus chrysogaster). Primates, 29, 129-134.

Redican, W. K. (1975). Facial expressions in nonhuman primates. In L. A. Rosenblum (Ed.), Primate behavior (Vol. 4, pp. 103-194). New York: Academic Press.

SMALL, M. (Ed.). (1984). Female primates: Studies by women primatologists. New York: Liss.

SoutHWICK, C. H. (1967). An experimental study of intragroup agonistic behavior in rhesus monkeys (Macaca mulatta). Behaviour, 28, 182-209.

Southwick, C. H., \& SidDiQI, M. F. (1972). Experimental studies on social intolerance in wild rhesus groups. American Zoologist, 12, 651-652.

(Manuscript received February 28, 1991.) 